\title{
International Negotiation: A Quarter Century of Research
}

Much can change over 25 years. When International Negotiation was established in 1996, it was just a few years after the breakup of the Soviet Union, the disintegration of the Eastern Bloc, and the founding of the European Union. Within a few years after publication began, international terrorist incidents grew rapidly, populist citizen-led protests resulted in the downfall of many governments, the use of information technology and social media mushroomed yielding countless new channels to communicate and organize, many new multinational regimes were formulated, and the rise of the Global South resulted in an upsurge of cooperation among developing countries, to name a few momentous events and trends. Many more critical changes in the global arena can be listed, all having important impacts on the processes and outcomes of international negotiation and mediation.

There are always new political, economic and social factors that can affect international negotiations. So, it is important for researchers and diplomats to stay attuned to changing situations and anticipate what they might mean for the detailed give-and-take of particular upcoming negotiations. Through its special thematic issues, as well as its unsolicited articles, the journal has sought to publish research that is evidence-based, forward-looking and practical, while pushing the boundaries of theory. At the same time, the journal has been proactive in looking back and reanalyzing several key areas in the international negotiation literature, to assess their continued relevance and add to our understanding. This includes articles on justice and fairness, postagreement negotiation, preventive diplomacy, negotiation styles and culture, and training and research methods, for example.

Change reveals itself in the what (different sectors and policy areas), the where (involving new countries and coalitions), the who (with greater inclusion of different stakeholders), and the why (for example, new threats or problem areas) of negotiation and how that impacts on ways the negotiation process unfolds. We have seen in recent years how the use of new social media technologies (Twitter and Facebook, for example) can influence elections, spur trade wars, and undo existing agreements, with little regard for country borders. We have seen how the emergence of populist leaders sometimes leads 
to autocratic regimes, and popular protests - like the Arab Spring, and the Orange, Rose, Velvet and Euromaidan revolutions - often result in complicated or disappointing conclusions. As such complex international issues evolve, they often require negotiation or mediation processes to resolve difficult conflicts and problems, and adapt to new circumstances.

The journal has published original research that draws upon existing theories and practitioner know-how, while encouraging the development of new theories and concepts, to extend and advance our understanding and explanation of future trends. International Negotiation offers these findings and insights in support of better academic knowledge, as well as improved practitioner techniques and approaches. To accomplish these goals, we bring together international negotiation experts from many different disciplines from political science, economics, sociology, anthropology, psychology, and the legal profession, among others. And we encourage contributions that analyze negotiation processes in many different sectors - resolving issues concerning the environment, the economy, business, trade, peace and conflict, non-proliferation and security, and international development, among others.

For this anniversary issue, we asked our Editorial Board and International Advisory Board members to each consider their areas of specialization and write short, thoughtful essays on how the context has evolved over the past quarter century and what that might mean for future research directions. The first five articles in this $25^{\text {th }}$ anniversary issue start from the premise that there has been a decline in multilateralism that has produced significant challenges to international negotiation practices. I. William Zartman examines how the current lack of order and predictability in international politics impacts on productive negotiation. Paul Meerts then discusses trends in the erosion of multilateral diplomacy, and J. P. Singh analyzes the breakdown of multilateralism in international trade negotiations. P. Terrence Hopmann analyzes growing challenges to future arms control negotiations in a context where many existing global regimes are collapsing. Bertram Spector assesses the growing tendencies of states to exit from international agreements and seek renegotiation from scratch instead of pursuing incremental adjustment through postagreement negotiation.

The next set of articles address other critical research issues. Christer Jönsson examines problems of credibility in international negotiation in a time when technological advances facilitate deception. Valérie Rosoux analyzes the concept of long-term justice in international negotiation where certain historical grievances persist. Guy Olivier Faure assesses how changes and constancies of cultural drivers have impacted China's strategies and tactics in the international negotiation arena. Daniel Druckman reviews research insights 
on key negotiation factors, such as group attachments, turning points, social justice, values and interest, and conceptual learning to assess what remains to be analyzed. Lastly, Larry Crump examines the evolving tools required to manage complex negotiations effectively.

Many thanks go out to our Editorial Board and International Advisory Board members, authors and reviewers who have contributed articles, organized special thematic issues, engaged in peer reviews, and encouraged scholars and practitioners to submit articles over the years. Also, we are grateful to the Conflict Management Program at the Johns Hopkins University School of Advanced International Studies for providing editorial assistants and venues for Board meetings. Lastly, we greatly appreciate the support and encouragement we have received from our publisher, Brill/Nijhoff, and its publishing and editorial staff for the past 25 years and onwards.

\author{
Bertram I. Spector \\ Editor-in-Chief
}

